\title{
MENINGKATKAN SINERGI ORANG TUA DAN GURU DALAM PROGRAM DETEKSI PERKEMBANGAN ANAK
}

\author{
Vera Firdaus \\ Program Studi Manajemen, Universitas Muhammadiyah Sidoarjo \\ *e-mail: verafirdaus06@gmail.com ${ }^{1}$
}

\begin{abstract}
Changes that occur in the child's growth and development phase are the result of the maturation process and the learning process. There needs to be a harmonious synergy between parents and teachers to optimize children's development, psychological and physical functions of children. There are children's problems, including: independence, difficulty adapting, temper tantrums, lack of discipline, indulgence, so a program is needed to provide solutions to these problems. This community service provides solutions through the Child Development Detection Program, Counseling and Parenting in 3 kindergarten school locations in Jember. The method used is a qualitative approach. The data were collected through observation, interviews and documentation, then analyzed descriptively. The results of the data indicate the achievement of the program. Community service is able to bridge the perceptions of parents and teachers so that synergies and effective communication are established in order to optimize children's development
\end{abstract}

Keywords: Synergy, Development Detection, Parenting, Counseling

\begin{abstract}
Abstrak
Perubahan yang terjadi pada fase tumbuh kembang anak merupakan hasil dari proses pematangan (maturation) dan proses belajar learning process. Perlu sinergi yang harmonis antara orang tua dan guru untuk mengoptimalkan perkembangan anak, fungsi psikologis dan fisik anak. Terdapat permasalahan anak antara lain : ketidakmandirian, kesulitan berdaptasi, , temper tantrum, kurang disiplin, pemanjaan, sehingga diperlukan program untuk memberikan solusi permasalahan tersebut. Pengabdian masyarakat ini memberikan solusi melalui Program Deteksi perkembangan anak, Konseling dan Parenting di 3 lokasi sekolah TK di jember. Metode yang dilakukan menggunakan pendekatan kualitatif. Data dari dikumpulkan melalui observasi, wawancara dan dokumentasi, kemudian dianalisis secara deskriptif. Hasil data menunjukkan ketercapaian program. Pengabdian masyarakat mampu menjembatani persepsi orang tua dan guru sehingga terjalin sinergi dan komunikasi yang efektif demi mengoptimalkan perkembangan anak.
\end{abstract}

Kata kunci: Sinergi, Deteksi Perkembangan, Parenting, Konseling

\section{PENDAHULUAN}

Sebagai individu yang lahir unik dengan segenap potensi dan kepribadian yang dimilikinya, anak perlu mendapat dukungan, stimulasi serta pola asuh yang kondusif untuk mengoptimalkan potensi, karakter dan tumbuh kembang anak. Secara sistematis perubahan pada setiap tahapan tumbuh kembangnya akan mengalami proses pematangan dan mempengaruhi tugas pada fase perkembangan berikutnya (Jannah, 2015). Perubahan yang terjadi pada fase tumbuh kembang anak merupakan hasil dari pematangan fungsi psikis dan fisik yang dipengaruhi proses pematangan (maturation process) dan proses belajar learning process. Lingkungan rumah maupun sekolah menjadi tempat bagi proses pematangan dan belajar anak (Erzad, 2017). 
Orang tua merupakan lingkungan terdekat yang selalu mengitarinya dan sekaligus menjadi first model. Gaya pengasuhan orang tua terutama ibu akan mempengaruhi tumbuh kembang anak. Salah satu problem dalam pengasuhan anak adalah kurangnya pemahaman orang tua tentang kebutuhan anak sesuai dengan fase perkembangan beserta karakteristik perilakunya (Hurlock, 1991). Kurangnya pemahaman dan pengetahuan tentang kebutuhan perkembangan anak menyebabkan orang tua merefleksikan pola asuhnya dalam bentuk perlakuan fisik dan psikis yang cenderung kurang tepat (Novrinda, Kurniah, \& Yulidesni, 2017).

Hasil observasi dan konseling pada beberapa sekolah-sekolah TK di Jember justru memperlihatkan bahwa pola asuh yang tidak tepat menimbulkan permasalahan pada anak antara lain tidak mandiri, tidak bisa mengendlikan emosi, temper tantrum, hambatan interaksi dengan teman sebaya. Hal inilah yang kemudian menimbulkan stres bagi orang tua dalam pengasuhan kepada anak. Padahal stres pengasuhan ini akan dapat diatasi oleh orang tua manakala orang tua memiliki coping skills, problem solving, dan child behavioral problems (Mawardah, Siswati, \& Hidayati, 2012). Ini menunjukkan bahwa dalam mendukung tumbuh kembang anak diperlukan keterampilan dan pengetahuan dengan mengacu pada kebutuhan perkembangan anak sesuai dengan usianya (fase tumbuh kembangnya).

Pendidikan pra sekolah menjadi lingkungan yang kondusif dalam menstimulasi perkembangan anak. Hal ini karena proses belajar di sekolah diolah dalam bungkus aktivitas bermain, sehingga proses belajar berjalan alami dan terarah. Pendidikan pra-sekolah, baik di Taman Kanak-kanak maupun Play group memiliki pengaruh besar untuk menstimulasi dan mengoptimalkan tumbuh kembang anak. Menurut (Septiani, Widyaningsih, \& Igomh, 2016), dalam pendidikan pra sekolah anak dioptimalkan perkembangan aspek motorik, personal sosial dan Bahasa.

Data survei Sosial Ekonomi Nasional (Susenas) memberikan gambaran bahwa 1 dari 4 atau 27,68 persen anak usia dini menempuh pendidikan pra sekolah (Taman Kanak-kanak dan Pendidikan Anak Udia Dini) (BPS, 2020). Berikut Hasil Survey Susenas tentang Persentase Anak Usia Dini yang Pernah/Sedang Mengikuti PAUD Menurut Karakteristik Demografi :

Tabel 1. Persentase anak usia dini yang mengikuti PAUD berdasarkan tipe daerah

\begin{tabular}{llcccc}
\hline Karakteristik & \multicolumn{5}{c}{ Jenis Pendidikan Pra Sekolah } \\
\cline { 2 - 5 } $\begin{array}{c}\text { Demografi/ } \\
\text { Tipe Daerah }\end{array}$ & TK & RA/BA & $\begin{array}{c}\text { PAUD/ PAUD } \\
\text { Terintegrasi } \\
\text { BKB/Posyandu }\end{array}$ & $\begin{array}{c}\text { KELOMPOK } \\
\text { BERMAIN }\end{array}$ & $\begin{array}{c}\text { Taman } \\
\text { Penitipan } \\
\text { Anak }\end{array}$ \\
\hline Perkotaan & 72,46 & 6,74 & 17,88 & 2,44 & 0,48 \\
\hline Pedesaan & 70,80 & 5,37 & 21,80 & 1,89 & 0,15 \\
\hline
\end{tabular}

Sumber : (BPS, 2020)

Data tersebut menunjukkan bahwa jumlah anak usia dini yang bersekolah di pendidikan pra sekolah di perkotaan sedikit lebih besar (yaitu sebesar 1,57 persen) daripada di pedesaan. Ini memberikan gambaran bahwa baik di perkotaan maupun di pedesaan, orang tua telah memiliki kesadaran untuk memberikan pendidikan pra sekolah pada anaknya. Hal ini karena orang tua mulai menyadari pentingnya pendidikan pra memberikan manfaat baik jangka pendek maupun jangka panjang bagi anak. Dalam jangka pendek pendidikan anak terbukti meningkatkan kompetensi anak ketika memasuki sekolah dasar (Muhtadi, 2010). Sedangkan dalam jangka panjang pendidikan mampu memberikan proses pematangan bagi perkembangan motorik, intelektual/kognitif, bahasa serta interaksi sosial anak. 
Namun demikian, kesadaran akan pentingnya pendidikan pra sekolah bagi anak belum ditunjang oleh pemahaman orang tua akan perkembangan anak. Orang tua masih terjebak oleh persepsi bahwa pendidikan yang menjadi kebutuhan anak usia dini adalah belajar membaca, menulis dan berhitung saja. Kesardaran akan pentingnya stimulasi atau pendidikan yang mendukung proses pematangan dan proses belajar pada anak usia dini di sekolah belum dipahami oleh orang tua. Persepsi orang tua yang hanya berfokus pada pendidikan secara kognitif saja (membaca, menulis, berhitung), menjadikan situasi yang tidak optimal bagi proses belajar anak. Orang tua cenderung memaksakan belajar, ditambah lagi metode yang monoton, membuat anak menjadi cepat bosan dan sulit memusatkan perhatian (Ismaniar, Jamaris, \& Wisroni, 2018).

Terdapat beberapa hambatan dalam upaya sekolah untuk mengoptimalkan pendidikan yang tepat bagi tumbuh kembang anak, antara lain kurangnya sinergi antara orang tua dan guru yang disebabkan oleh hambatan dalam berkomunikasi; belum terciptanya kesamaan persepsi dalam memahami tumbuh kembang anak; serta kesulitan guru dalam menemukan cara terbaik untuk menyampaikan berbagai tujuan pembelajaran di sekolah

Dengan latar belakang permasalahan tersebut maka diperlukan program yang mampu menjembatani komunikasi antara orang tua dan guru agar tercipta sinergi yang harmonis. Program yang dilaksanakan juga harus mampu memberikan transfer of knowledge bagi orang tua dalam guru dalam memahami anak. Upaya pengabdian ini akan menjadi optimal manakala program diawali dengan deteksi perkembangan anak atau peserta didik, sehingga diketahui kelebihan serta kelemahan anak. Deteksi perkembangan anak akan memberikan deskripsi bagi orang tua dan guru tentang potensi serta permasalahan anak. Karena setiap anak memiliki keunikan (individual deferences), maka solusi yang diberikan akan disesuaikan dengan permasalahan anak, dalam bentuk konseling dan tips yang tertera pada laporan hasil deteksi perkembangan anak.

\section{METODE PELAKSANAAN}

Program pengabdian masyarakat ini dilaksanakan dengan menjalin kerja sama dengan 3 sekolah di Kabupaten Jember Pada setiap sekolah yang menjadi tempat pelaksanaan pengabdian ini memiliki sekolah Taman Kanak-kanak dan Kelompok Bermain (Play Group). Kegiatan pengabdian masyarakat ini dilaksanakan di TK Al Hujjah Jember; TK Pertiwi di Mayang Jember; TK Al Azhar Jember.

Metode pelaksanaan pengabdian menggunakan metode pendekatan kualitatif yaitu dengan melakukan pengumpulan data secara triagulasi. Pengumpulan data menggunakan observasi, wawancara dan dokumentasi baik dari studi pendahuluan, konseling, parenting dan deteksi perkembangan anak. Data yang diperoleh dari kegiatan-kegiatan tersebut dianalisis secara deskriptif, agar dapat menyajikan temuan sebagai jawaban dari tujuan dan rumusan masalah. Dengan demikian dapat terukur ketercapaian keberhasilan kegiatan pengabdian masyarakat. Tolok ukur keberhasilan pengabdian masyarakat di Kabupaten Jember ini adalah perubahan perilaku dan sikap dari orang tua. Tingkat ketercapaian tersebut dapat diketahui dari : (1) Meningkatnya Pemahaman orang tua tentang fase tumbuh kembang anak; (2) Perubahan sikap orang tua dalam menerapkan pola asuh kepada anaknya 
(3) Terjalinnya komunikasi yang efektif dan harmonis antara orang tua dan guru agar terjadi keselarasan dalam mengoptimalkan pembelajaran bagi anak.

\section{HASIL DAN PEMBAHASAN}

Kegiatan pengabdian masyarakat ini dimaksudkan untuk transfer of knowledge. Dengan demikian baik orang tua maupun guru memiliki pemahaman tentang tumbuh kembang anak dengan didukung oleh data dari anak serta pengetahuan tentang tugas perkembangan anak sesuai tahapan usianya. Program pengabdian ini mampu memberikan perubahan perilaku dan sikap orang tua, sehingga meminimalisisr permasalahan tumbuh kembang anak. serta mampu memberikan stimulasi terhadap potensi yang dimiliki anak. Dalam jangka pendek kegiatan pengabdian ini mampu mensinergikan persepsi orang tua dan guru dalam memahami tumbuh kembang anak.

Untuk mencapai tujuan kegiatan pengabdian masyarakat, maka kegiatan dilaksanakan melalui tahapan-tahapan kegiatan yan terdiri dari Program Deteksi perkembangan anak, Konseling dan Parenting. Berikut adalah tahapan program dan uraian kegiatan pengabdian masyarakat.

\section{Studi Pendahuluan}

Pengabdian masyarakat ini diawali dengan studi pendahuluan guna mengidentifikasi permasalahan serta mendiskusikan tujuan kegiatan. Dengan demikian kegiatan akan lebih terarah dan menjawab permasalahan. Hasil diskusi bersama kepala sekolah, guru, dan staf di tiga sekolah di Kabupaten Jember yaitu Al Hujjah, TK Pertiwi Mayang dan TK Al Azhar. Pelaksanaan kegiatan dimulai pada 22 Januari 2020 hingga 11 Maret 2021. Dari hasil diskusi diperoleh gambaran tentang permasalahan anak di sekolah antara lain : Kemandirian, perbedaan pola asuh orang tua, belum memahami perintah, kesulitan beradaptasi dan bersosialisasi, belum terbangun pembiasaan belajar rutin dan menyenangkan, push parenting, temper tantrum, kurang disiplin, pemanjaan, kurangnya komunikasi orang tua dengan guru.

Dari berbagai permasalahan tersebut kemudian disepakati program Deteksi perkembangan anak melalui tes psikologi dan observasi guru di kelas. Kegiatan konseling dilakukan secara tertutup/individual (saat psikotes individual pada anak) dan konseling yang dilakukan secara terbuka saat parenting. Program berikutnya adalah parenting yang temanya ditentukan oleh sekolah.

2. Deteksi Tumbuh Kembang Anak

Tujuan dari deteksi perkembangan anak anak untuk memahami potensi, kelemahan serta permasalahan anak. Hal ini dimaksudkan sebagai data awal agar memahami keunikan anak. Hasil kegiatan ini adalah laporan tes psikologi yang diberikan kepada orang tua. Dalam laporan disertakan pula saran parenting bagi orang tua sesuai dengan assessment tes psikologinya. Sedangkan hasil observasi guru sebagai bahan analisis saat rapat sekolah dan bahan kajian dalam penentuan tema parenting.

Deteksi perkembangan anak dilakukan melalui psikotes secara individual dan observasi guru. Guna mengotimalkan proses deteksi dan validitas psikotes, maka psikotes hnya dibatasi 8 orang dalam 1 hari. Untuk itu guru menjadwalkan terlebih dahulu agar anak dan orang tua tidak menunggu lama. Penentuan waktu juga disesuaikan jam sekolah, agar anak dalam kondisi nyaman. Kendala dari pelaksanaan psikotes manakala Anak 
ngambek, rewel, sulit memahami perintah, atau tantrum. Maka untuk menyiasati hal ini ditentukan jadwal tambahan apabila anak tidak bisa mengikuti psikotes. Pelaksanaan psikotes diawali tanggal 22 Januari 2020 di TK Al Azhar Jember. Di TK Pertiwi Mayang Jember psikotes dimulai tanggal 15 Maret 2020. Sedangkan psikotes hari pertama di TK Al Hujjah Jember tanggal 3 Juli 2020.

Ringkasan hasil deteksi perkembangan anak disampaikan dalam bentuk laporan kepada masing-masing orang tua mengingat sifat laporan psikotes adalah rahasia. Komponen tes psikologi yang diungkap adalah Aspek Motorik, Aspek Verbal, Aspek Kognitif dan Aspek Sosial. Dari ke empat aspek tersebut kemandirian menjadi fokus perhatian orang tua dan guru. Karena permasalahan utama pada anak di awal sekolah adalah kemandiria. Selain itu kemandirian mempengaruhi konsentrasi dan kemampuan sosialisasi pada anak usia dini. Secara garis besar, berikut adalah gambaran hasil psikotes tentang aspek kemandirian anak.

Tabel 2. Hasil Deteksi Perkembangan Anak Tantang Kemandirian

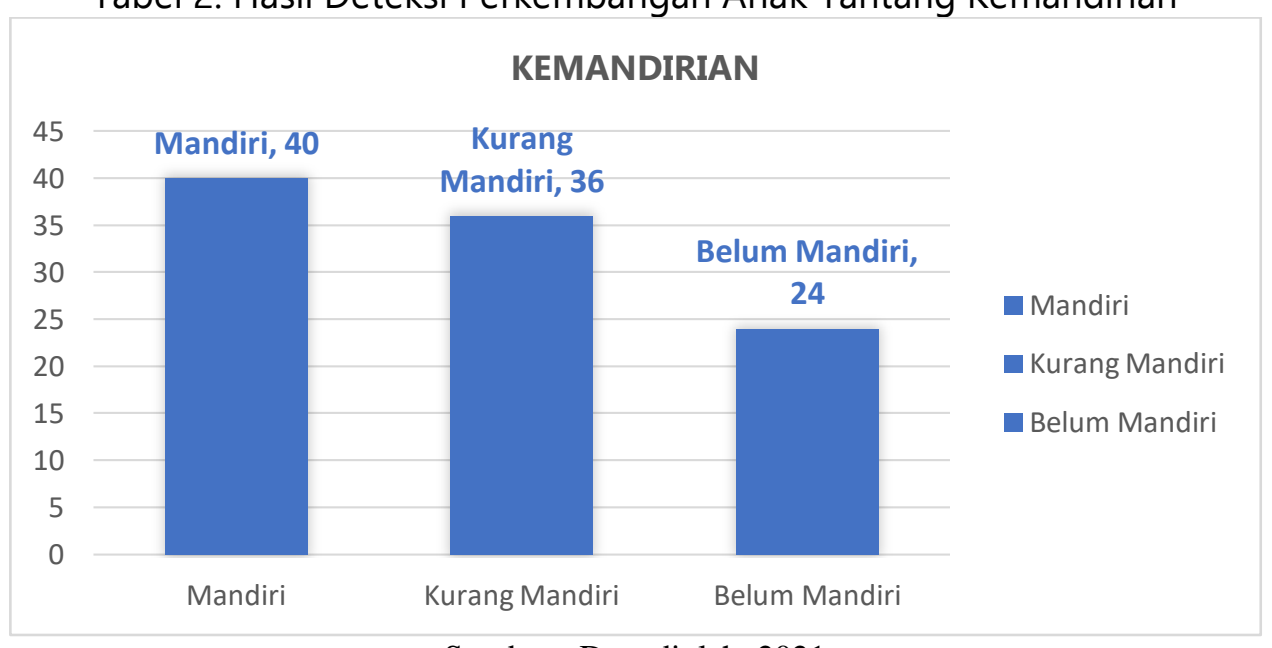

Sumber : Data diolah, 2021

Dari tabel 2 tersebut menunjukkan bahwa hanya 40 persen anak yang sudah mandiri. Sebanyak 36 persen anak sedang belajar untuk mandiri, sedangkan 24 persen anak belum mandiri. Pada anak yang belum mandiri inilah yang memerlukan dukungan orang tua mengingat pada anak tersebut memerlukan dorongan menyesuaikan diri dengan situasi sekolah. Anak yang belum mandiri juga perlu sinergi dalam berkomunikasi sehingga anak dapat merasakan attachment (kelekatan) bukan hanya dengan orang tau melainkan juga dengan guru

3. Konseling

Kegiatan konseling dalam pengabdian masyarakat ini dimaksudkan untuk pendalaman terhadap masalah yang dialami anak dan persepsi orang tua. Konseling dilakukan secara tertutup (secara indivual) saat psikotes atau sesuai perjanjian waktu yang disepakati. Konseling juga dilakukan saat parenting, yaitu saat sesi tanya jawab. Konseling bagi orang tua atau wali murid ini dihadiri oleh orang tua, dan beberapa diantaranya dihadiri orang tua pengganti, misalnya nenek, kakek, tante. Dalam setiap kegiatan tentunya ada tujuan pelaksanaan kegiatan agar kegiatan lebih terarah dan bermakna.

Tujuan konseling bagi orang tua antara lain: (1) Membantu orang tua dalam menghadapi masalah yang berhubungan dengan anak (2) Membantu dalam memperoleh pengertian tentang masalah anak serta bantuan-bantuan yang dapat diberikan (saran) (3) 
Membantu membina hubungan baik antara orang tua murid dengan pihak sekolah, terutama dalam masalah-masalah yang berkenaan dengan anak (4) Membantu memberikan pengertian pada orang tua terhadap program pendidikan.

4. Parenting

Kegiatan Parenting dilaksanakan di tiga sekolah Taman Kanak-kanak, yang dilaksanakan di awal semester pembelajaran. Isi materi parenting disesuaikan dengan permasalahan di sekolah. Tema parenting antara lain : Masa Peka Belajar, datanglah; Membangun Emosi Poisitif Anak; Bantu Aku Mandiri; Ayahku Tersayang, Ibuku Tercinta Kaulah Teladanku; Child Ebuse, Tumbuh Kembang Anak; Setiap Anak Istimewa, Komunikasi Yang Mencerdaskan. Tujuan parenting adalah : (1) Menyamakan persepsi tentang pola asuh anak antara pihak sekolah dengan orang tua; (2) Menjelaskan tentang psikologi perkembangan anak (3) Memberikan tips atau saran tentang permasalahan tumbuh kembang anak (4) Konsultasi terbuka bagi wali murid (5) Memberikan gambaran tentang pola pembelajaran di sekolah. Berikut adalah foto kegiatan parenting.

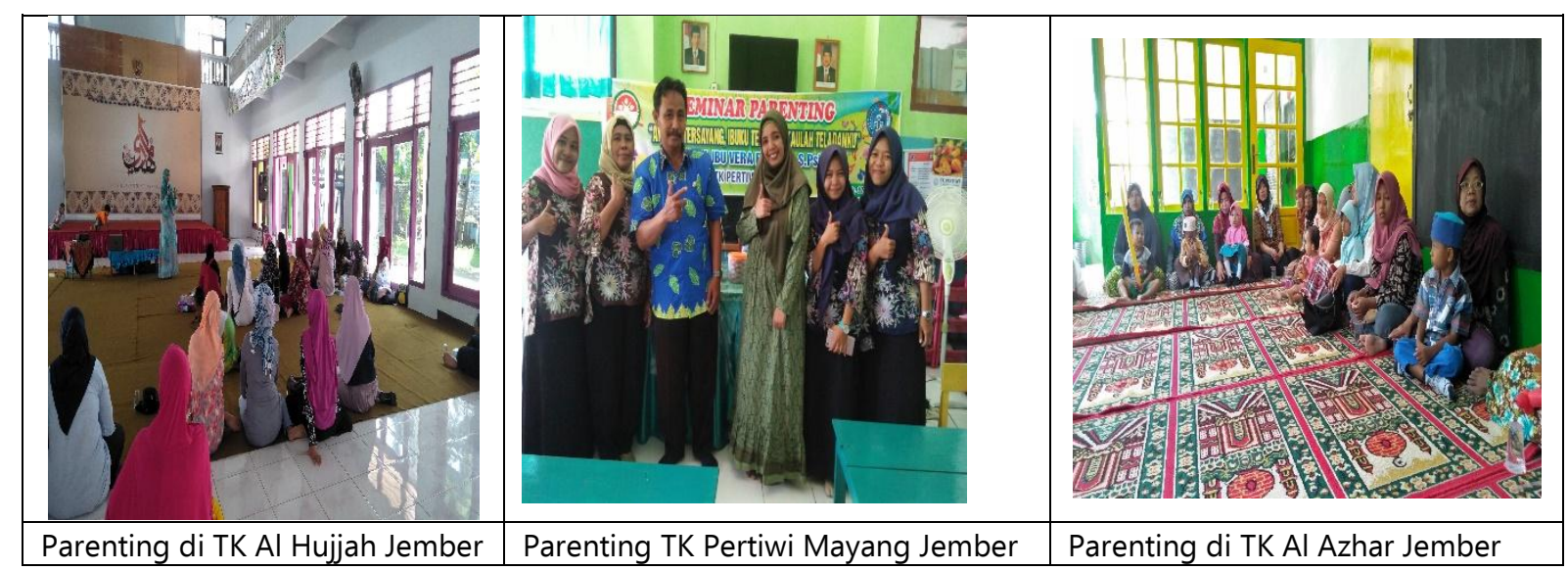

\section{Evaluasi Program}

Pelaksanaan kegiatan pengabdian masyarakat ini diakhiri dengan tahapan terakhir yaitu Evaluasi program. Tanggapan positif baik dari orang tua maupun sekolah dapat terlihat pada hasil pooling berikut ini :

Tabel 3. Hasil Pooling Orang tua Tentang Kegiatan Parenting

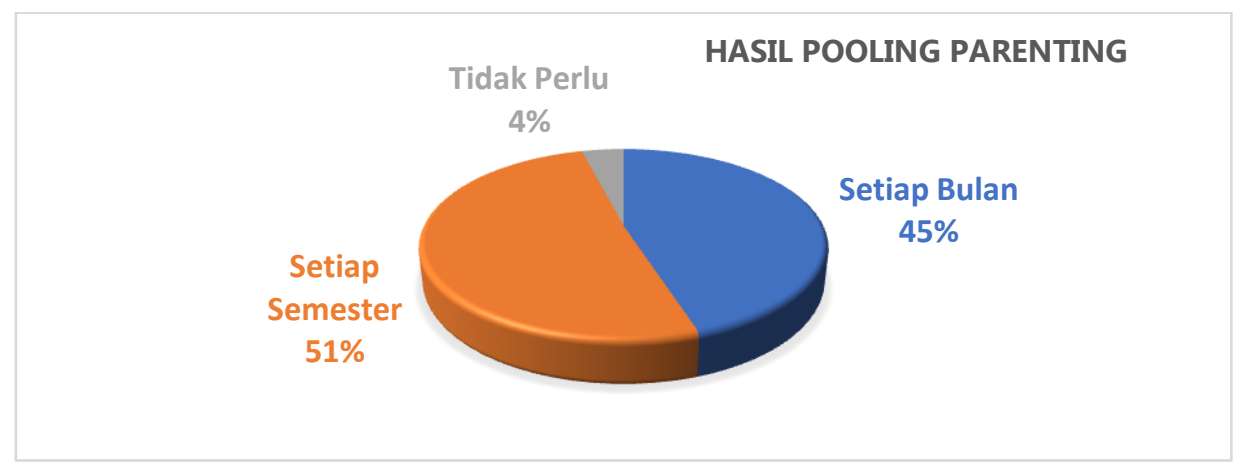

Sumber : Data diolah, 2021

Dari hasil pooling yang diberikan kepada orang tua tentang perlunya parenting dalam kegiatan sekolah, sebanyak 96 persen setuju Parenting diadakan kembali, dan sebanyak 4 
persen menyatakan tidak perlu ada parenting. Orang tua yang menyatakan setuju diadakan parenting mengusulkan parenting diadakan 1 kali dalam 1 semester, namun ada pula yang mengusulkan setiap bulan. Respon yang positif juga diberikan oleh pihak sekolah yang berharap kerja sama tersebut tetap dilanjutkan. Hal ini dibuktikan dengan kesepakatan (MOU) bersama.

\section{KESIMPULAN}

Dalam upaya mengoptimalkan tumbuh kembang anak usia dini yang sedang mengikuti pendidikan pra sekolah di Taman Kanak-kanak, maka diperlukan kegiatan yang dapat membantu mensinergikan pihak sekolah (guru) dengan orang tua. Kegiatan pengabdian masyarakat dengan program deteksi tumbuh kembang ana,k konseling, dan parenting. Dengan program pengabdian ini masyarakat khususnya orang tua akan mampu memahami perkembangan anak, memberikan pola asuh dan bimbingan yang tepat sesuai kebutuhan anak. Sinergi yang terjalin melalui kegiatan pengabdian ini mampu mengharmonisasikan dan menyamakan persepsi orang tua dan guru terhadap pendidikan dan pembelajaran yang baik bagi perkembangan anak.

\section{UCAPAN TERIMA KASIH}

Ucapan terima kasih kepada Kepala sekolah, guru dan segeanap staf di TK Al Hujjah, Jember; TK Al Azhar Jember;serta TK Pertiwi Mayang Jember, atas kerja samanya selama pengabdian masyarakat ini berlangsung.

\section{DAFTAR PUSTAKA}

BPS. (2020). Profil Anak Usia Dini 2020. Subdirektorat Statistik Pendidikan dan Kesejahteraan Sosial. Jakarta: Badan Pusat Statistik. Retrieved Desember 2020

Erzad, A. M. (2017). Peran Orang Tua Dalam Mendidik. Jurnal Inovasi Pendidikan Guru Raudhatul Athfal, 5, 414-431. doi:http://dx.doi.org/10.21043/thufula.v5i2.3483

Hurlock, E. B. (1991). Psikologi Perkembangan Suatu Pendekatan Sepanjang Rentang Kehidupan (V ed.). Jakarta: Erlangga.

Ismaniar, Jamaris, \& Wisroni. (2018). Pentingnya Pemahaman Orang Tua Tentang Karakteristik Pembelajaran Aud Dalam Penerapan Model Environmental Print Berbasis Keluarga. KOLOKIUM, Jurnal Pendidikan Luar Sekolah, 6, 93-100. doi:10.5281/zenodo.1465447

Jannah, M. (2015). Tugas-tugas Perkembangan Pada Usia Kanak-kanak. Gender Equality: International Journal of Child and Gender Studies, 1, 87-98. Retrieved September 1, 2015

Mawardah, U., Siswati, \& Hidayati, F. (2012). Relationship Between Active Coping With Parenting Stress In Mother Of Mentally Retarded Child. Jurnal Empati, 1, 1-14. Retrieved Oktober 2012

Muhtadi, A. (2010). Metode Pembelajaran Untuk Meningkatkan Kesiapan Sekolah Pada Program Pendidikan Anak Pra-Sekolah. MAJALAH ILMIAH PEMBELAJARAN, 1-12. Retrieved Mei 2010 
Novrinda, Kurniah, N., \& Yulidesni. (2017, Januari). Peran Orang Tua Dalam Pendidikan Anak Usia Dini Ditinjau Dari Latar Belakang Pendidikan. Jurnal Potensia, 2, 39-46.

Septiani, R., Widyaningsih, S., \& Igomh, M. B. (2016). Tingkat Perkembangan Anak Pra Sekolah Usia 3-5 Tahun Yang Mengikuti Dan Tidak Mengikuti Pendidikan Anak Usia Dini (PAUD). Jurnal Keperawatan J, 4, Hal 114 -. Retrieved November 2016 